\title{
ОЦЕНКА ВЛИЯНИЯ БЕНЗ(А)ПИРЕНА НА БИОЛОГИЧЕСКУЮ АКТИВНОСТЬ ЧЕРНОЗЕМА РОСТОВСКОЙ ОБЛАСТИ
}

\author{
Минникова Татьяна Владимировна, \\ lok0261008@yandex.ru \\ Сушкова Светлана Николаевна, \\ terra_rossa@mail.ru \\ Манджиева Саглара Сергеевна, \\ msaglara@mail.ru
}

\author{
Минкина Татьяна Михайловна, \\ tminkina@mail.ru
}

\author{
Колесников Сергей Ильич, \\ kolesnikov@sfedu.ru \\ 1 Южный федеральный университет, Россия, \\ 344090, г. Ростов-на-Дону, пр. Стачки, 194/1.
}

\begin{abstract}
Актуальность исследования обусловлена необходимостью оценить влияние многолетнего токсического загрязнения полициклическими ароматическими углеводородами с использованием ярового ячменя (Hordeum sativum distichum) на ферментативную активность черноземов и морфометрические показатели ячменя. Яровой ячмень использовали для оценки отрицательного влияния загрязнения чернозема бензо[а]пиреном как признанным канцерогеном и мутагеном среди полициклических ароматических углеводородов. Выбранные дозы были близки к уровню техногенного давления в исследуемой зоне - 0-800 мкг кг ${ }^{-1}$ бензо[а]пирена. Содержание бензо[а]пирена в почве в течение 4 лет эксперимента повлияло на морфометрические показатели ячменя и его поглощение растениями, а также на ферментативную активность почв.
\end{abstract}

Цель: оценить влияние бензо [а] пирена на биологическую активность чернозема Ростовской области.

объекты. Исследования проводились с образцом почвы, отобранным из верхнего (0-20 см) слоя чернозема обыкновенного карбонатного тяжелосуглинистого на территории Государственного почвенного заповедника «Персиановская заповедная степь», расположенного в Ростовской области (юг Российской Федерации), вдали от источников загрязнения. Данная почва имеет следующие характеристики: $C_{\text {org }}-3,4$ \% pH - 7,3, емкость катионного обмена - 37,1 ммоль (+)/100 г; содержание СаСО - 0,1\%, содержание физической глины - 53,1\%.

Методы. Модельные эксперименты проводили в естественных условиях. Два килограмма воздушно-сухой почвы просеивали через сито диаметром 1 мм и помещали в вегетационные сосуды объемом 4 литра. Раствор бензо[а]пирена в ацетонитриле перемешивали с почвой для создания концентраций бензо[а]пирена в образцах почвы, равных 20, 200, 400 и 800 мкг кг ${ }^{-1}$ (сухой вес), что соответствует 1, 10, 20 и 40 уровням предельно-допустимой концентрации бензо[а]пирена, соответственно. Незагрязненная почва использовалась в качестве контроля, фоновым образцом служил образец с внесением ацетонитрила аналогично образцам с бензо[а]пиреном.

Результаты. Основным фактором, обуславливающим увеличение содержания бензо[а]пирена в черноземе обыкновенном и растениях модельного эксперимента, была доза внесения токсиканта в чернозем обыкновенный. Активность оксидоредуктаз (каталазы и дегидрогеназы) чернозема была ингибирована с ростом содержания бензо[а]пирена в почве. Наибольшее токсическое действие бензо[а]пирена оказал на активность дегидрогеназ. Тенденции выраженной фитотоксичности почв наблюдали для всех морфометрических показателей ярового ячменя, таких как энергия прорастания, длина побегов, вес растений и длина колоса. Количественные уровни поглощения бензо[а]пирена корнями ярового ячменя превышали уровни поглощения в вегетативной части более чем в 2,5 раза во всех загрязненных вариантах. Таким образом, переход бензо[а]пирена в побеги и корни ярового ячменя из чернозема, сопровождающийся ингибированием активности дегидрогеназы и каталазы, демонстрирует оценку воздействия полютанта на живые организмы.

\section{Ключевые слова:}

Бенз(а)пирен, почва, яровой ячмень, морфометрия, активность каталазы,

активность дегидрогеназ, корреляционная зависимость.

\section{Введение}

Полициклические ароматические углеводороды (ПАУ) являются одними из наиболее существенных загрязняющих веществ окружающей среды, оказывающих мутагенное и канцерогенное воздействие на все живые организмы [1]. Содержание 16 приоритетных соединений ПАУ в объектах окружающей среды контролируется международными законами и нормативами за счет их канцеро- генности, мутагенности и токсичности [2-5]. По своей физической и химической форме ПАУ достаточно гидрофобны и устойчивы в объектах окружающей среды, особенно при загрязнении почвы благодаря сложной структуре почвенной матрицы [6]. Оценка закономерностей распределения ПАУ в системе почва-растение является одним из основных показателей в системе мониторинга состояния окружающей среды $[7,8]$. 
Бензо [а] пирен (БаП) является главным маркером загрязнения почвенно-растительной системы ПАУ [9]. Исследования особенностей накопления в системе почва-растение БаП необходимо для нормирования содержания соединения в почве и минимизации риска воздействия на компоненты экосистем и человека $[10,11]$. Содержание БаП во всех экологических системах и пищевых продуктах находится под обязательным контролем во всем мире [3, 12].

Присутствие БаП в почвах, растениях и воде связано с повышенным уровнем техногенного давления. Аккумуляция БаП на поверхности почвы связана с процессами распределения в системе почва-растение и миграцией в почвенном профиле. Способность БаП к накоплению в растениях и миграции в почве в основном зависит от сорбционных свойств почвенной матрицы, а также от физических и химических свойств молекул БаП (прежде всего водорастворимости) и способности перехода в почвенный раствор [13]. Фоновое содержание БаП в растениях и большинстве минеральных почв колеблется в пределах 0,1-5 мкг кг ${ }^{-1}$, тогда как для некоторых черноземов и торфяных почв характерен более высокий уровень накопления БаП - 15-20 мкг кг ${ }^{-1}$. Это связано с увеличением содержания концентрированных органических веществ и специфической структурой почвенного микробного сообщества. Процесс комплексного взаимодействия почв и растений является важным объектом для контроля загрязнения окружающей среды БаП [14].

Почвенные частицы сорбируют соединения ПАУ, что вызывает высокую доступность данных соединений для растений и влияет на ферментативную активность почв [15-18]. Почвенные микробные сообщества могут вызвать разрушение ПАУ внеклеточными ферментами, такими как оксидоредуктазы [19]. Такие лигнинолитические ферменты, как пероксидаза и фенолоксидаза, изза сходных структур ПАУ и лигнина (полифенольных единиц) и их низкой субстратной специфичности способны окислять подобные органические загрязнители. Усиление активности окислительновосстановительных ферментов может быть обусловлено ростом числа микробных сообществ, ответственных за деградацию и трансформацию органических загрязнителей почвы, что вызвано добавлением доступного источника углерода.

Ризосфера почв оказывает стимулирующее действие на почвенные микроорганизмы, в том числе почвенные ферменты. Показано, что в ризосфере присутствует повышенное количество микроорганизмов по сравнению с остальной почвой [20]. Наиболее оптимальным подходом в целях фиторемедиации является увеличение объема корневой системы за счет тонких прикорневых волосков $[21,22]$. Ризоремедиация - это тип процесса фиторемедиации с использованием микроорганизмов, который вызывает деградацию загрязняющих веществ [23].
Благодаря своей химической структуре ПАУ при попадании в почву сорбируется на органических и неорганических почвенных коллоидах, что уменьшает биодоступность данных органических соединений в качестве субстратов для микроорганизмов. Накопление ПАУ в почвенной среде ухудшает ее биологические параметры, такие как ферментативная активность и количество почвенных микроорганизмов [24-27]. Так, активность почвенной уреазы не представляет полной информации обо всех метаболических процессах, однако тесно связана с содержанием углерода, общего и аммиачного азота [28, 29]. Уровни органического углерода имеют особое значение. Добавление в почву органического вещества снижает неблагоприятное воздействие ПАУ на активность уреазы и влияние органического вещества на биохимические свойства почвы, что определяется видом и концентрацией ПАУ [30].

Настоящее исследование направлено на исследование биологической активности чернозема обыкновенного при загрязнении БаП в модельном эксперименте на основе особенностей накопления, фитотоксичности и деградации БаП, а также изучения изменений ферментативной активности в почве в уникальных условиях модельного эксперимента с искусственным загрязнением БаП. Содержание БаП в почве и растениях модельного эксперимента определяли с использованием нового экологически чистого метода субкритической водной экстракции, использованной вместо традиционных методов экстракции БаП с использованием высокого количества органических растворителей.

\section{Материалы и методы}

Исследования проводились с образцом почвы, собранным из верхнего (0-20 см) слоя карбонатного тяжелосуглинистого чернозема на территории Государственного почвенного заповедника «Персиановская заповедная степь», расположенного в Ростовской области (к югу от Российской Федерации), вдали от источников загрязнения. Данная почва имела следующие физико-химические характеристики: $\mathrm{C}_{\text {org }}-3,4 \%, \mathrm{pH}-7,3$, емкость катионного обмена (ЕКО) - 37,1 ммоль $(+) 100 \Gamma^{-1}$; содержание $\mathrm{CaCO}_{3}-0,1 \%$, содержание физической глины - 53,1\% [31].

Модельные эксперименты были заложены в 2011 г. и проводились в естественных условиях. Два килограмма воздушно-сухой почвы просеивали через сито диаметром 1 мм и помещали в вегетативные горшки объемом 4 литра. Раствор БаП в ацетонитриле смешивали с почвой для получения конечных концентраций БаП в образцах, равных 20, 200, 400 и 800 мкг БаП на кг почвы (сухой вес), что соответствовало $1,10,20$ и 40 уровням предельно-допустимых концентраций (ПДК), соответственно. Чистую почву использовали в качестве контроля. В качестве фона использовали почву, на поверхность которой вносили ацетонитрил - 
растворитель БаП. Каждый образец почвы отбирали в трехкратной повторности.

Выбор концентраций БаП в образцах почвы модельного эксперимента был обоснован уровнями содержания БаП в почвах, расположенных в окрестностях техногенных источников, таких как крупные электростанции, производящих энергию с использованием низкокачественного угля [32]. Исследования механизмов воздействия различных концентраций БаП на почву важны для понимания основных особенностей накопления, миграции и трансформации БаП в техногенно загрязненных почвах [33, 34].

Сосуды с почвой, загрязненной БаП, инкубировали в условиях, близких к естественным, на экспериментальной площадке Южного федерального университета, в течение 4,5 лет (56 месяцев). Для соблюдения естественных микробиологических процессов почву в сосудах увлажняли дистиллированной водой для поддержания оптимальной влажности. Каждую весну (через 8, 20, 32 и 44 месяца после начала инкубации) образцы почвы были засеяны яровым ячменем (Hordeum sativum distichum) «Одесский-100» (30 семян на сосуд). Перед засевом ячменя образцы почвы в вегетационных сосудах смешивали и отбирали для определения концентрации БаП. Через 4 месяца растения ячменя извлекали из сосудов с почвой, очищали от частиц почвы, измеряли морфометрические показатели, высушивали на воздухе, взвешивали, сушили, просеивали через сито диаметром 1 мм и анализировали содержание БаП. В данной статье представлены результаты исследований содержания БаП в почве и растениях через 4,5 года с момента закладки модельного опыта. Данный срок позволил рассмотреть состояние БаП в почве и его биодоступность после многолетней инактивации поллютанта в условиях модельного опыта.

Экстракиия БаП субкритической водой. Экстракция БаП методом субкритической водной экстракции была использована для извлечения поллютанта из образцов почв и растений $[35,36]$. Субкритическая водная экстракция БаП из образцов грунта проводилась в специально разработанном экстракционном картридже из нержавеющей стали и снабжена навинчивающимися колпачками на обоих концах экстракционного картриджа. Экстракционный картридж, содержащий образец и воду, помещали в печь, оборудованную регулятором температуры и давления [37, 38].

Анализ проб почвы и растений. Процесс анализа БаП в почвах на основе субкритической водной экстракции состоял из следующих поэтапных операций: воздушно-сухой образец почвы или растения измельчали в фарфоровой ступке и пропускали через сито 1 мм. Один грамм образца помещали в экстракционный картридж и добавляли 8 мл воды с двойной дистиллированной водой. Экстракцию проводили в оптимальных условиях (30 мин при $250{ }^{\circ} \mathrm{C}$ и 100 атм.). После охлаждения системы содержимое картриджа фильтровали в кониче- скую стеклянную колбу и промывали 2 мл дистиллированной воды. Данную операцию повторяли два или три раза, пока фильтрат не становился прозрачным.

Была проведена жидкостная повторная экстракция БаП из водного экстракта, поскольку БаП нерастворим в воде [39]. Затем проводят концентрирование полученного экстракта, его очистку колоночной хроматографией и определение БаП с помощью высокоэффективного жидкостного хроматографа (ВЭЖХ) с использованием флуориметрического детектирования. Процесс встряхивания смеси микрообъема БаП, экстрагированного в органическую матрицу, позволил непосредственно эмульгировать определяемый токсикант в водный раствор [40, 41]. Количество органического растворителя (матрицы) было достаточно высоким для извлечения молекул БаП, но в то же время недостаточным для концентрирования примеси (при самой интенсивной люминесценции), что позволило получить четко отделенную структуру спектров при люминесценции детектора ВЭЖХХ [42].

Водный раствор повторно экстрагировали три раза 5 мл н-гексана путем встряхивания в течение 15 мин в делительной воронке. Экстракты гексана объединяли и фильтровали через безводный $\mathrm{Na}_{2} \mathrm{SO}_{4}$, выпаривали досуха в грушевидной колбе на вакуумном испарителе на водяной бане при $40{ }^{\circ} \mathrm{C}$. Остаток растворяли в 1 мл ацетонитрила, встряхивая в течение 30 мин.

Содержание БаП в экстрактах определяли количественно с помощью ВЭЖХ (Agilent 1260, Germany) с одновременным обнаружением ультрафиолетового света (UV-1000) и флуоресценции (FL-3000) согласно требованиям ISO 13877 [43]. Длина волны возбуждения (FD) составила 264 нм, длина волны излучения - 408 нм. Пик БаП на хроматограммах экстрактов образцов почвы, идентифицированных путем сравнения времени удерживания с аналитическим стандартным образцом, определяли с использованием двух детекторов.

Физические и химические свойства почвы определяли стандартными методами [44]. Растворители и реагенты включали этанол (96\%, аналитический класс), н-гексан (99\%, аналитический класс), гидрат калия (98 \%, аналитический сорт), ацетонитрил (99,9 \%, аналитический сорт), $\mathrm{NaOH}$ $\left(97 \%\right.$, аналитический класс) и безводный $\mathrm{Na}_{2} \mathrm{SO}_{4}$. Стандарт БаП в ацетонитриле (Sigma-Aldrich CAS Number 50-32-8) с концентрацией 200 мкг см${ }^{-3}$ используется при подготовке стандартов для анализа ВЭЖХ.

Активность каталазы $\left(\mathrm{H}_{2} \mathrm{O}_{2}: \mathrm{H}_{2} \mathrm{O}_{2}\right.$ - оксидоредуктаза, КФ 1.11.1.6.) была определена газометрическим методом по А.Ш. Галстяну [45] по скорости разложения перекиси водорода (ГОСТ 177-88) при контакте с почвой. Активность выражали в мл $\mathrm{O}_{2} 1^{-1}$ г 1 мин $^{-1}$. Активность дегидрогеназы (субстрат: НАД (Ф) - оксидоредуктазы, КФ 1.1.1) определяли инкубированием в термостате в анаэробных условиях 2,3,5 трифенилтетразолия хлористого с 
использованием раствора глюкозы в качестве источника дегидрирования. Содержание в образцах почв трифенилформазанов (ТФФ) определяли после экстрагирования спиртом спектрофотометрически при длине волны 540 нм в кюветах 10 мм. Активность выражали в мг ТФФ $10^{-1}$ г 24 часа $^{-1}$.

Морфометрические показатели ярового ячменя изучались по методике В.В. Церлинга [46] в фазу полной спелости. Определялись: энергия прорастания, вес растения, высота растений, высота колоса с остями и без остей, высота побегов, длина корней.

Обработка данных и статистический анализ проводили с использованием STATISTICA 11.0.

\section{Результаты и их обсуждение}

Содержание бенз[а]пирена. Модельное загрязнение черноземов обыкновенных различными концентрациями БаП привело к ускоренной деструкции поллютанта в изученной почве в течение 4-х лет проведения модельного эксперимента. Основным фактором аккумуляции БаП в почвах и растениях модельного эксперимента была доза инокуляции токсиканта, которая способствовала сорбции ароматических молекул БаП, при удерживании на алюмосиликатной молекулярной решетке почв, что повлияло на прочность сорбции и биодоступность свободных БаП для растений. Поскольку фоновый уровень БаП в черноземе обыкновенном составил почти 1 ПДК, добавление 20 мкг кг БаП способствовало накоплению 37,4 мкг к ${ }^{-1}$ в первоначально загрязненной почве в первый год исследований (рис. 1).

Ранее было показано, что содержание БаП в почве, корнях и побегах ячменя в течение 4-х лет проведения исследования снижается [47]. Установлено, что концентрация БаП в загрязненной почве увеличивается прямо пропорционально уровню искусственного загрязнения БаП исходной почвы и составляет от 37,4 мкг кГ ${ }^{-1}$ в варианте 1 ПДК, 221,7 мкг кг ${ }^{-1}$ в варианте 10 ПДК, 406,0 мкг к $\Gamma^{-1}$ в варианте 20 ПДК, 743,4 мкг $к \Gamma^{-1}$ в варианте 40 ПДК. В первоначально загрязненных почвах обнаруживали от 84 \% (1 ПДК загрязненной почвы) до 99 \% (10 ПДК) от общей внесенной концентрации БаП в почву.

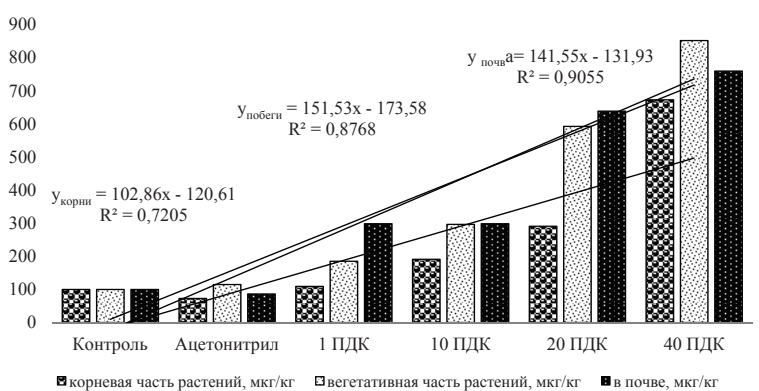

Pис. 1. Содержание бенз [a] пирена в корнях и побегах ячменя и почве, $л к 2 \cdot \kappa 2^{-1}$

Fig. 1. Benz [a] pyrene content in roots and shoots of barley and soil, $\mu g^{\prime} k g^{-1}$
Важной причиной деградации БаП в почве является воздействие корневых экссудатов растений, стимулирующих ферментную систему, способствующую деструкции БаП. Среди зерновых культур выделяют ячмень яровой как одну из наиболее информативных и чувствительных сельскохозяйственных культур при биодиагностике, способствующих деструкции БаП в почве [8]. Это подтверждается проведенными модельными исследованиями. Например, для варианта с максимальным загрязнением БаП - 40 ПДК, установлено повышение содержания БаП в корнях растений до 23,4 мкг кг ${ }^{-1}$ в первый год исследования, что составило более $3 \%$ от содержания БаП в почве, а в варианте 1 ПДК в первый год исследования содержание БаП в корнях растений достигало 6,4 \% от содержания БаП в почве. Таким образом, показано, что корневое поглощение БаП максимально в наименее загрязненных почвах и минимально при высоких концентрациях вносимого БаП в почву. Аналогичные тенденции были обнаружены при поглощении БаП растениями [48]. Уровень содержания БаП в вегетативной части растения достигал 1-4 \% , что значительно уступало содержанию БаП в корневой части растений. Полученные данные могут быть использованы для биоиндикации загрязненных почв и биоремедиации БаП.

Изленение морфолетрических характеристик ярового ячленя. В качестве наиболее чувствительных биоиндикационных характеристик при загрязнении БаП может быть выделена морфометрия ярового ячменя, которую определяли в период максимального вегетативного развития растений. Было обнаружено влияние загрязнения почвы БаП на общую длину ярового ячменя, начиная с уровня загрязнения 1 ПДК (20 мкг кг ${ }^{-1}$ БаП). Воздействие БаП на морфометрию растений при загрязнении различными дозами БаП показало высокий уровень корреляции между концентрацией БаП в почве и длиной ячменя, $\mathrm{R}^{2}=0,98$ (рис. 2, 3). Это подтверждает высокое фитотоксическое воздействие БаП на растения ячменя ярового: чем выше содержание БаП в почве, тем меньше длина растений ячменя ярового. Общая длина растений ячменя ярового за 4 года исследований коррелировала с содержанием БаП в почве. Для варианта 1 ПДК общая длина ячменя ярового достигла значений контрольного варианта через 4 года проведения модельного эксперимента [47]. Однако для вариантов, загрязненных в концентрациях 10, 20, 40 ПДК, общая длина ячменя ярового так и не достигла значений контрольного варианта, что свидетельствует о продолжающемся фитотоксическом воздействии БаП в данных вариантах даже после 4-х лет деструкции токсиканта. Вероятно, в ходе деградации БаП также образуются окисленные формы высокотоксичных метаболитов БаП, которые обуславливают продолжительный фитотоксический эффект для растений.

Установленное уменьшение суммарной высоты растений ячменя обусловлено снижением высоты 
остей, постепенно снижающейся с увеличением содержания БаП в почве и растениях. Измерения длины корней также показали прямую зависимость от уровня загрязнения почв БаП: при увеличении концентрации БаП установлено незначительное увеличение длины корней. Это может быть вызвано высокой канцерогенностью и мутагенностью БаП, а также образующихся в ходе деградации БаП других представителей ПАУ и их канцерогенных метаболитов. Так, в исследовании Н.A. Hernández-Ortega et al. [49] корни 10-дневных сеянцев Medicago sati$v a$ потеряли тонус сосудистой системы за счет роста сосудов метаксилемы при загрязнении дизельным топливом [50], что свидетельствует о возможном мутагенном эффекте на корневую систему растений при загрязнении ПАУ.

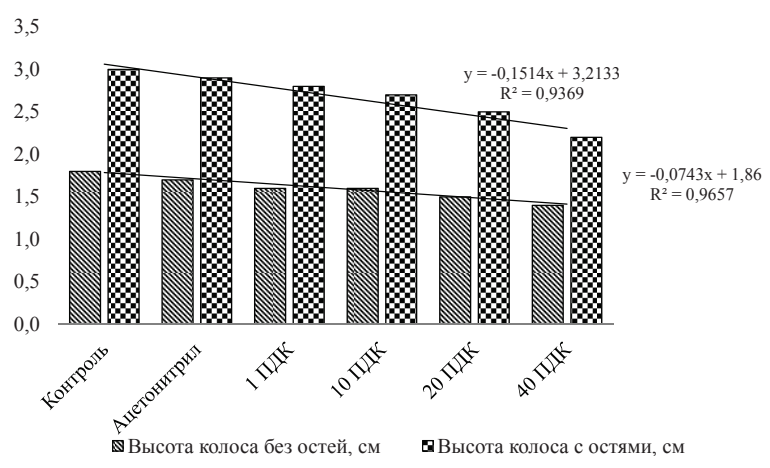

Puc. 2. Изленение высоты колоса с остяли и без остей ячменя в зависилости от содержания бенз [а]пирена в почве, см

Fig. 2. Change in ear height with or without awn of barley, depending on benzo[a]pyrene content in soil, $\mathrm{cm}$



Pис. 3. Изленение высоты побегов и длины корней ячленя в зависимости от содержания бенз[а]пирена в почве, см

Fig. 3. Change in shoot height and root length of barley, depending on benzo[a]pyrene content in soil, $\mathrm{cm}$

Установлено снижение энергии прорастания ячменя ярового [31] при увеличении концентрации БаП в почве (рис. 4). На 4-й год проведения модельного эксперимента энергия прорастания увеличилась, что может быть связано со снижением уровня БаП в изученных почвах.

Общая масса растений ячменя имела обратную корреляционную зависимость с уровнем загрязнения почв БаП. Показано, что общая масса ячменя уменьшается с увеличением концентрации БаП (рис. 5).

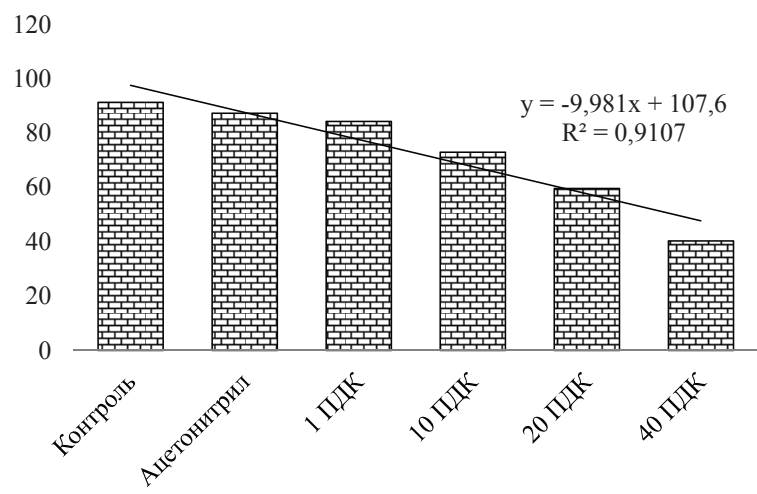

Рис. 4. Изленение энергии прорастания ячленя при различных концентрациях бенз [а]пирена, \%

Fig. 4. Change in barley germination energy for various concentrations of benzo[a]pyrene, $\%$

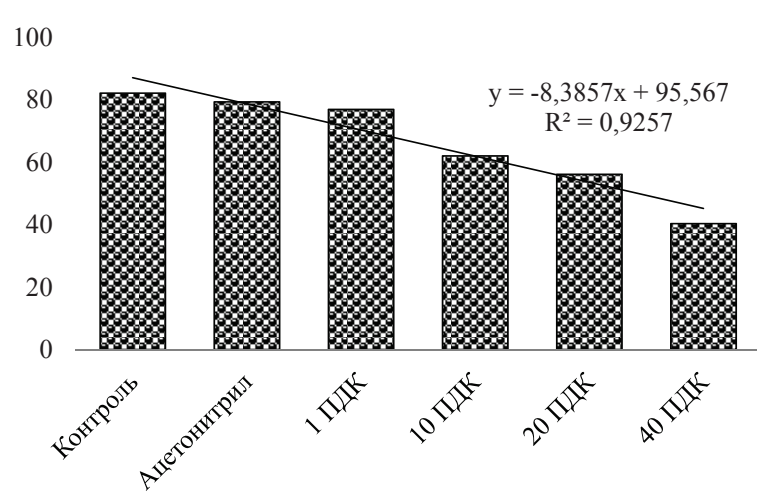

Pис.5. Изменение массы ячменя в зависимости от содержания бенз[а]пирена в почве, г

Fig. 5. Change in barley phytomass depending on benz[a]pyrene content in soil, $g$

Таким образом, при анализе морфобиометрических характеристик ячменя ярового, выращенного на почвах, искусственно загрязненных БаП, показано снижение массы растений с увеличением содержания БаП в почве (от 1 до 40 ПДК), что связано со снижением высоты побегов и колоса с остями на 38 и $26 \%$, соответственно. Однако показано увеличение длины корней на $16 \%$ при 20 и 40 ПДК по сравнению с контролем, что может быть обусловлено усиленным делением клеток камбия корневой системы ячменя и, как следствие, утончением корня за счет увеличения его длины. Функциональные способности корня в случае подобной стимуляции вызывают усиление сорбции БаП за счет увеличения площади всасывания корневых волосков. Показатель интенсивности начального роста - энергия прорастания - демонстрирует снижение всхожести семян ячменя до 60 \% в максимально загрязненном варианте по сравнению с контролем. Подобные процессы могут быть связаны с нарушением функций антиоксидантных ферментов растений, вызванные токсическим эффектом влияния БаП. В работе F. Bernard с соавторами [51] показано на примере брокколи (Brassica oleracea) и клевера белого (Trifolium repens), что именно биохимический уровень сопро- 
тивления окислительному стрессу (Reactive Oxygen Species) имеет наибольшее влияние на степень нарушения морфологической структуры растения [49].

Ферлентативная активность. Полициклические ароматические углеводороды как любые химические загрязнители оказывают воздействие на окислительные и восстановительные процессы в почвах [51-54]. Однако, учитывая специфическое биологическое действие БаП на биологическое состояние почв, следует изучить информативность использования активности таких оксидоредуктаз, как каталаза и дегидрогеназа. Поскольку БаП - это органическое соединение, содержащее углерод, с молекулярной массой 252,31 г моль-1, и может служить источником углерода для ферментных систем, активность дегидрогеназы, как экзофермента, является информативным биологическим показателем загрязнения почвы БаП. С увеличением содержания БаП в почве до 10 ПДК существенных изменений в активности дегирогеназ замечено не было, что обусловлено повышением содержания ризосферных выделений растений, стимулирующих ферментативную деятельность дегидрогеназ, а также ростом активности ферментов за счет использования БаП в качестве источника углерода при невысоком содержании БаП в почве [35]. Однако при концентрации 20 и 40 ПДК БаП установлено значительное ингибирование активности дегидрогеназ по сравнению с контролем (рис. 6).

Установлено снижение активности каталазы при увеличении содержания БаП в почвах модельного эксперимента. Установлено снижение активности каталазы по сравнению с контрольным вариантом для всех загрязненных почв БаП для вариантов 1, 10, 20 и 40 ПДК: на 1, 17,5, 28,0 и 47,3\% , соответственно.

Корреляиионная зависилость. Составлена корреляционная матрица между содержанием БаП в корнях, побегах, почве модельного эксперимента и весом растений, энергией прорастания семян яч- меня, высотой колоса без остей, высотой колоса с остями, высотой побегов и длиной корней, в которой отмечена очень тесная отрицательная связь между содержанием БаП в корнях, побегах и почве и энергией прорастания семян, весом растений, высотой колоса с остями и без остей, высотой побегов $(\mathrm{R}=-0,82-0,99)$, а также тесная и очень тесная положительная связь между содержанием БаП в корнях, побегах и почве и длиной корневой системы растений ячменя $(\mathrm{R}=0,75-0,85)$ (табл. 1$)$. Содержание БаП в почве имело прямую корреляционную зависимость с содержанием БаП в побегах и корнях ячменя $(R=0,89-0,98)$. Подобные зависимости отражают процессы биоаккумуляции БаП растениями, описанные в ряде работ [55-57].

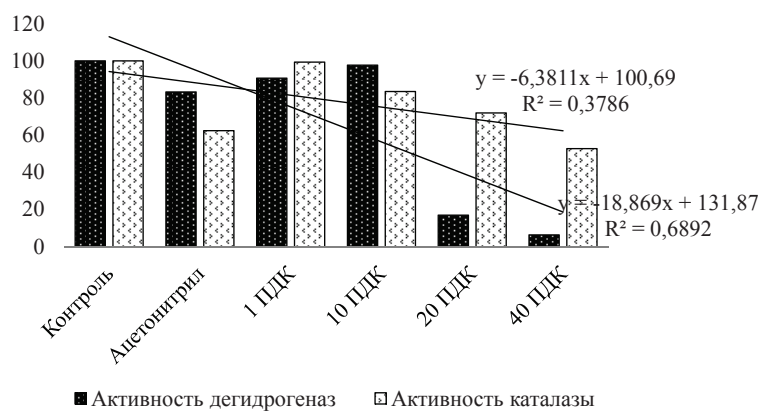

Pис. 6. Изменение активности дегидрогеназ и каталазы почв в зависилости от содержания бенз[а]пирена в почве, \% от контроля

Fig. 6. Changes in activity of dehydrohenases and catalase of soils depending on benzo[a]pyrene content in soil, \% of control

При сравнении связей между ферментативной активностью почв и содержанием БаП в почве, побегах и корнях установлено снижение активности дегидрогеназ при повышении содержания БаП в корнях растений $(\mathrm{R}=-0,83)$, вегетативной части растений $(R=-0,92)$, почве $(R=-0,91)$ (табл. 2$)$. Показана тенденция к снижению активности окислительно-восстановительного фермента - каталазы, при повышении содержания БаП в почве.

таблица 1. Корреляционная матрица между содержанием бенз[а]пирена в почве и морфометрическими показателями ячленя

Table 1. Correlation matrix between benz [a]pyrene content in soil and morphometric parameters of barley

\begin{tabular}{|c|c|c|c|c|c|c|c|c|}
\hline \multicolumn{6}{|c|}{$\begin{array}{c}\text { Морфометрические показатели } \\
\text { Morphometric parameters }\end{array}$} & \multicolumn{3}{|c|}{$\begin{array}{c}\text { Содержание БаП } \\
\text { BaP content }\end{array}$} \\
\hline Вес растений & Энергия прорастания & Высота колоса без остей & Высота колоса с остями & Высота побегов & Длина корней & Корни & Побеги & Почва \\
\hline Plant weight & Germination energy & Ear height & Ear height with awns & Shoot height & Root length & Roots & Shoots & Soil \\
\hline \multicolumn{9}{|l|}{1,00} \\
\hline 0,99 & 1,00 & & & & & & & \\
\hline 0,93 & 0,94 & 1,00 & & & & & & \\
\hline 0,98 & 0,99 & 0,97 & 1,00 & & & & & \\
\hline 0,99 & 1,00 & 0,93 & 0,99 & 1,00 & & & & \\
\hline$-0,82$ & $-0,83$ & $-0,65$ & $-0,77$ & $-0,79$ & 1,00 & & & \\
\hline$-0,94$ & $-0,96$ & $-0,85$ & $-0,95$ & $-0,97$ & 0,75 & 1,00 & & \\
\hline$-0,97$ & $-0,99$ & $-0,93$ & $-0,99$ & $-0,99$ & 0,85 & 0,96 & 1,00 & \\
\hline$-0,94$ & $-0,96$ & $-0,95$ & $-0,97$ & $-0,95$ & 0,78 & 0,89 & 0,98 & 1,00 \\
\hline
\end{tabular}

Примечание. Расчет проводили по абсолютныл показателям: вес растений (2), энергия прорастания (\%), высота колоса без остей и с

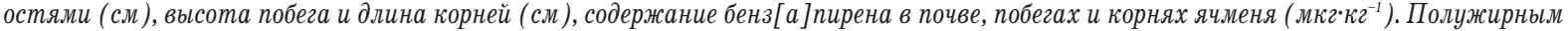
шрифтом выделены достоверные отличия.

Note. Calculation was carried out in absolute terms: weight of the plants (g), germination energy (\%), ear height without sprouts and with awns $(\mathrm{cm})$, shoot height and length of roots $(\mathrm{cm})$, benz [a ]pyrene content in soil, barley shoots and roots $\left(\mu \mathrm{g}^{\circ} \cdot \mathrm{kg}^{-1}\right)$. Significant differences are in bold. 
Таблица 2. Корреляиионная матрииа между содержанием бенз [а]пирена и ферментативной активностью почв

Table 2. $\quad$ Correlation matrix between benz [a] pyrene content and enzymatic activity of soils

\begin{tabular}{|c|c|c|c|c|}
\hline $\begin{array}{c}\text { Ферментативная активность } \\
\text { Enzymatic activity }\end{array}$ & \multicolumn{3}{|c|}{$\begin{array}{c}\text { Содержание БаП } \\
\text { ВаP content }\end{array}$} \\
\hline $\begin{array}{c}\text { дегидрогеназ } \\
\text { dehydrogenases }\end{array}$ & $\begin{array}{c}\text { каталаза } \\
\text { catalase }\end{array}$ & $\begin{array}{c}\text { корни } \\
\text { roots }\end{array}$ & $\begin{array}{c}\text { побеги } \\
\text { shoots }\end{array}$ & $\begin{array}{c}\text { почва } \\
\text { soil }\end{array}$ \\
\hline 1,00 & & & & \\
\hline 0,66 & 1,00 & & & \\
\hline$-0,83$ & $-0,63$ & 1,00 & & \\
\hline$-0,92$ & $-0,58$ & $\mathbf{0 , 9 5}$ & 1,00 & \\
\hline$-0,91$ & $-0,40$ & $\mathbf{0 , 8 8}$ & $\mathbf{0 , 9 7}$ & 1,00 \\
\hline
\end{tabular}

Примечание. Расчет проводили по абсолютным показателям: ак тивность дегидрогеназ, мг ТФФ·10 $2^{-1} \cdot 24$ часа $^{-1}$, активность ка талазы мл $\mathrm{O}_{2} \cdot 12^{-1} \cdot 1$ мин $^{-1}$, содержание бензо [а] пирена в почве, поб-

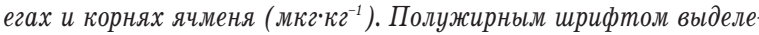
ны достоверные отличия.

Note. Calculation was carried out in absolute terms: dehydrogenases activity, mg TPP $10 \mathrm{~g}^{-1} \cdot 24$ hours $^{-1}$, catalase activity $\mathrm{ml} \mathrm{O}_{2} 1 \mathrm{~g}^{-1}$ for $1 \mathrm{~min}^{-1}$, benzo[a]pyrene content in soil, shoots and barley roots $\left(\mu \mathrm{g}^{\circ} \mathrm{kg}^{-1}\right)$. Significant differences are in bold.

\section{Заключение}

Таким образом, проведена оценка влияния БаП на биологическую активность чернозема обыкновенного и морфометрические показатели ярового ячменя спустя 4 года после внесения поллютанта в почву модельного эксперимента с загрязнением различными дозами БаП с ежегодным высевом ячменя ярового. Установлено, что основным фактором накопления БаП в почвах и растениях модель-

\section{СПИСОК ЛИТЕРАТУРЫ}

1. Tsibart A., Gennadiev A. Polycyclic aromatic hydrocarbons in soils: Sources, behavior, and indication significance // Eurasian Soil Science. - 2013. - V. 46 (7). - P. 728-741.

2. Jian Y. Photomutagenicity of 16 polycyclic aromatic hydrocar bons from the US EPA priority pollutant list // Mutation Research. - 2004. - V. 557 - P. 99-108.

3. Analytical methods for polycyclic aromatic hydrocarbons (PAHs) in food and the environment needed for new food legislation in the European Union / T. Wenzl, R. Simon, J. Kleiner, E. Anklam // Trend Analytic Chemistry. - 2006. - V. 25 (7). - P. 716-725.

4. Some non-heterocyclic polycyclic aromatic hydrocarbons and some related exposures // Monographs on the Evaluation of Carcinogenic Risks to Humans. - Lyon (FR): IARC, 2010. - V. 92. $862 \mathrm{p}$.

5. Lamichhane S., Krishna K.B., Sarukkalige R. Polycyclic aromatic hydrocarbons (PAHs) removal by sorption: a review // Chemosphere. - 2016. - V. 148. - P. 336-353.

6. Antizar-Ladislao B., Lopez-Real J., Beck A. Degradation of polycyclic aromatic hydrocarbons (PAHs) in an aged coal tar contaminated soil under in-vessel composting conditions // Environmental Pollution. - 2006. - V. 141 (3). - P. 459-468.

7. Bioaccumulation of polycyclic aromatic hydrocarbons in the soilplant systems of the northern-taiga biocenoses / E.V. Yakovleva, V.A. Beznosikov, B.M. Kondratenok, D.N. Gabov // Eurasian Soil Science. - 2012. - V. 45 (3). - P. 309-320.

8. Biodegradation of Benzo(a)pyrene by biofilm forming and plant growth promoting Acinetobacter sp. strain PDB4 / R. Kotoky, S. Das, L.P. Singha, P. Pandey, K.M. Singha // Environmental Technology \& Innovation. - 2017. - V. 10. - P. 256-268. ного эксперимента была доза внесения токсиканта. Несмотря на длительный период инкубации БаП в почве наблюдается достаточно высокое содержание поллютанта в почвах и накопление его в растениях. Установлен длительный токсический эффект влияния поллютанта на условия прорастания ярового ячменя, что подтверждается снижением морфометрических показателей ярового ячменя по сравнению с контролем.

Активность дегидрогеназ и каталазы ингибируется с увеличением дозы бенз[а]пирена. Максимальное токсическое воздействие БаП оказал на активность дегидрогеназ при дозах 20 и 40 ПДК, что составило 83 и $93 \%$, относительно контроля. При анализе морфометрических характеристик ячменя ярового, выращенного на почвах, искусственно загрязненных БаП, показано снижение массы растений с увеличением содержания БаП в почве (от 1 до 40 ПДК), что связано со снижением высоты побегов и колоса с остями на 38 и $26 \%$, соответственно. Однако показано увеличение длины корней на $16 \%$ при 20 и 40 ПДК по сравнению с контролем. Энергия прорастания показала снижение всхожести семян ячменя более чем $60 \%$ в максимально загрязненном варианте по сравнению с контролем.

Исследование поддержано Министерством образования и науки РФ № 5.948.2017/ПЧ и грантами Президента РФ (НШ-3464.2018.11; МК-2973.2019.4). Исследования выполнены на оборудовании ЦКП Южного федерального университета "Высокие технологии», "Биотехнология, биомедииинский и экологический мониторинг».

9. How the sorption of benzene in soils contaminated with aromatic hydrocarbons is affected by the presence of biofuels / M. Carvalho, M. Vila, F. Rohden, M. Rosas, J. Dias, T. Oliva-Teles, A. Danko, C. Delerue-Matos, A. Fiuza // Eurasian Journal Soil Science. - 2015. - V. 4 (2). - P. 111-117.

10. Maliszewska-Kordybach B., Smreczak B., Klimkowicz-Pawlas A. The levels and composition of persistent organic pollutants in alluvial agriculture soils affected by flooding // Environmental Monitoring Assessment. - 2013. - V. 185 (12). - P. 9935-9948.

11. Monitoring researches of the benzo[a]pyrene content in soils under the influence of the technogenic zone / T. Minkina, S. Sushkova, S. Mandzhieva, I. Tjurina, 0. Filonova // Middle East Journal of Scientific Research. - 2013. - V. 17 (1). - P. 44-49.

12. Department for Environment, Food and Rural Affairs and the Environment Agency. Contaminants in soil: collation of toxicological data and intake values for humans. Benzo[a]pyrene. Technical report. - Bristol: Bristol Environment Agency, 2002. - 30 p.

13. Пространственное варьирование содержания бенз (а) пирена и свойств агрозема вблизи Южно-сахалинской ТЭЦ / Д.Н. Липатов, А.И. Щеглов, Д.В. Манахов, Ю.А. Завгородняя, П.Т. Брехов // Почвоведение. - 2015. - № 5. - С. 633-641.

14. Bioaccumulation of polycyclic aromatic hydrocarbons in the soilplant systems of the northern-taiga biocenoses / E.V. Yakovleva, V.A. Beznosikov, B.M. Kondratenok, D.N. Gabov // Eurasian Soil Science. - 2012. - V. 45 (3). - P. 309-320.

15. Polycyclic aromatic hydrocarbons in the soils of technogenic landscapes / D. Gabov, V. Beznosikov, B. Kondratenok, E. Yakovleva // Geochemical International. - 2010. - V. 48 (6). - P. 569-579.

16. Gennadiev A., Tsibart A. Pyrogenic polycyclic aromatic hydrocarbons in soils of reserved and anthropogenically modified areas: 
Factors and features of accumulation // Eurasian Soil Science. 2013. - V. 46 (1). - P. 28-36.

17. Aranda R., Martinez-Pagán P. Methodology for the detection of contamination by hydrocarbons and further soil sampling for volatile and semi-volatile organic enrichment in former petrol stations, SE Spain // Eurasian Soil Science. - 2012. - V. 1 (1). P. $10-15$.

18. Anthracene and benzo (a) pyrene degradation in soil is favoured by compost amendment: Perspectives for a bioremediation approach / D. Baldantonia, R. Morellia, A. Bellinoa, M. Vittoria Prati, A. Alfania, F. de Nicolac // Journal of Hazardous Materials. 2017. - V. 339. - P. 395-400.

19. Bioaugmentation and biostimulation effects on PAH dissipation and soil ecotoxicity under controlled conditions / H. Hamdi, S. Benzarti, L. Manusad 'zianas, I. Aoyama, N. Jedidi // Soil Biology and Biochemistry. - 2007. - V. 39. - P. 1926-1935.

20. Rhizosphere geometry and heterogeneity arising from root-mediated physical and chemical processes / P. Hinsinger, G.R. Gobran, P.J. Gregory, W.W. Wenzel // New Phytology. - 2005. V. 168 (2). - P. 293-303.

21. Variation in root traits associated with nutrient foraging among temperate pasture legumes and grasses / Z. Yang, R. Culvenor, R. Haling, A. Stefanski, M. Ryan, G. Sandral, D. Kidd, H. Lambers, R. Simpson // Grass Forage Science. - 2015. - V. 72. - P. 93-103.

22. Growth and root dry matter allocation by pasture legumes and a grasswith contrasting external critical phosphorus requirements / R.E. Haling, Z. Yang, N. Shadwell, R.A. Culvenor, A. Stefanski, M.H. Ryan, G.A. Sandral, D.R. Kidd, H., Lambers R.J. Simpson // Plant Soil. - 2016. - V. 407 (1-2). - P. 67-79.

23. Bisht S. Bioremediation of polyaromatic hydrocarbons (PAHs) using rhizosphere technology // Brazilian Journal Microbiology. - 2015. - V. 46 (1). - P. 7-21.

24. Wyszkowska J., Wyszkowski M. Influence of petroleum - derived substances on number of oligotrophic and copitrophic bacteria in soil // American-Eurasian Journal of Agricultural \& Environmental Sciences. - 2008. - V. 2 (2). - P. 172-179.

25. Interactive effect of dissolved organic matter and phenanthrene on soil enzymatic activities / X. Zhan, W. Wu, L. Zhou, J. Liang, T. Jiang // Journal Environmental Science. - 2010. - V. 22 (4). P. 607-614.

26. Influence of xenobiotic contaminants on landfill soil microbial activity and diversity / M.I. Perez-Leblic, A. Turmero, M. Hernandez, A.J. Hernandez, J. Pastor, A.S. Ball, J. Rodriguez, M.E. Arias // Journal Environmental Management. - 2010. V. $30(1)$ - P. 285-290.

27. Hawrot-Paw M., Martynus M. The influence of diesel fuel and biodiesel on soil microbial biomass // Polish Journal of Environmental Studies. - 2011. - V. 2 (20). - P. 497-501.

28. Bielińska E.J., Żukowska G. Activity of protease and urease in light soil fertilized with sewage sludge // Agrophysica. - 2002. V. 70. - P. 41-47.

29. Wyszkowska J., Wyszkowski M. Activity of soil dehydrogenases, urease and acid and alkaline phosphatases in soil polluted with petroleum // Journal of Toxicology and Environmental Health. 2010. - V. 73. - P. 1202-1210.

30. Application of different organic amendments in a gasoline contaminated soil: Effect on soil microbial properties / M. Tejada, J.L. Gonzalez, M.T. Hernandez, C. Garcia // Bioresource Technology. - 2008. - V. 99. - P. 2872-2880.

31. ГОСТ 17.4.1.02.-83. Сохранение. Почвы. Классификация химических веществ для борьбы с загрязнением. - М.: ИД «Стандарт», 2008. -8 c.

32. Ion association in water solution of soil and vadose zone of chestnut saline solonetz as a driver of terrestrial carbon sink / A.A. Batukaev, A.P. Endovitsky, A.G. Andreev, V.P. Kalinichenko, T.M. Minkina, Z.S. Dikaev, S.S. Mandzhieva, S.N. Sushkova // Solid Earth. - 2016. - V. 7 (2). - P. 415-423.
33. Effect of an Attendant Anion on the Balance of Cations in the Soil-Solution System with an Ordinary Chernozem as an Example / T. Minkina, D. Pinsky, S. Mandzhieva, T. Bauer, S. Sushkova, A. Kushnareva // Eurasian Soil Science. - 2014. - V. 47 (8). P. $772-780$.

34. Monitoring of benzo[a]pyrene content in soils under the effect of long-term technogenic poluttion / S. Sushkova, T. Minkina, I. Turina, S. Mandzhieva, T. Bauer, R. Kizilkaya, I. Zamulina // Journal Geochemical Exploration. - 2017. - V. 174. - P. 100-106.

35. New method for benzo[a]pyrene analysis in plant material using subcritical water extraction / S. Sushkova, G. Vasilyeva, T. Minkina, S. Mandzhieva, I. Tjurina, S. Kolesnikov, R. Kizilkaya, T. Askin // Journal Geochemical Exploration. - 2014. - V. 144 (P. B). - P. 267-272.

36. New alternative method of benzo[a]pyrene extractionfrom soils and its approbation in soil under technogenic pressure / S.N. Sushkova, T.M. Minkina, S.S. Mandzhieva, G.K. Vasilyeva, N.I. Borisenko, I.G. Turina, R. Kizılkaya // Journal of Soils and Sediments. - 2016. - V. 16 (4). - P. 1323-1329.

37. Extraction of quercetin from Polygonum hydropiper L. by subcritical water. American / A. Lekar, S. Borisenko, E. Vetrova, S. Sushkova, N. Borisenko // Journal of Agricultural and Biological Science. - 2013 - V. 9 (1). - P. 1-5.

38. Approbation of express-method for benzo [a] pyrene extraction from soils in the technogenic emission zone territories / S. Sushkova, T. Minkina, S. Mandzhieva, N. Borisenko, G. Vasilyeva, R. Kızılkaya, T. Aıkın // Eurasian Journal Soil Science. 2015. - V. 4 (1). - P. 15-21.

39. Dadkhah A., Akgerman A. Hot water extraction with in situ wet oxidation: Kinetics of PAHs removal from soil // Journal Hazard Materials. - 2006. - V. 137 (1). - P. 518-526.

40. Pilot-scale subcritical water remediation of polycyclic aromatic hydrocarbon- and pesticide-contaminated soil / A. Lagadec, D. Miller, A. Lilke, S. Hawthorne // Environ Science Technology. - 2000. - V. 34 (8). - P. 1542-1548.

41. Latawiec A., Reid B. Sequential extraction of polycyclic aromatic hydrocarbons using subcritical water // Chemosphere. - 2010. V. 78 (8). - P. 1042-1048.

42. Galkin A., Lunin V. Water in sub- and supercritical conditions is a univer-salfluid for implementation of chemicalreactions // Success Chem. - 2005. - V. 74 (1). - P. 24-40.

43. ISO 13877-2005. Soil quality - Determination of polynuclear aromatic hydrocarbons. Method using high -performance liquid chromatography. $-2005 .-15 \mathrm{p}$.

44. Агрохимические методы исследования почв / под ред. А.В. Соколова. - М.: Наука, 1975. - 656 с.

45. Галстян А.ШІ. Ферментативная активность почв Армении. Ереван: Айастан, 1974. - 275 с.

46. Церлинг В.В. Диагностика питания сельскохозяйственных культур. Справочник. - М.: Агропромиздат, 1990. - 236 с.

47. Influence of PAH contamination on soil ecological status / S.N. Sushkova, T. Minkina, I. Deryabkina (Turina), S. Mandzhieva, I. Zamulina, T. Bauer, G. Vasilyeva, E. Antonenko, V. Rajput // Journal of Soils and Sediments. - 2018. - V. 18 (6). P. 2368-2378.

48. Мониторинг содержания бенз (а) пирена в почвах под влиянием многолетнего техногенного загрязнения / С.Н. Сушкова, Т.М. Минкина, С.С. Манджиева, И.Г. Тюрина, Г.К. Васильева, Р. Кизилкая // Почвоведение. - 2017. - V. 1. - С. 105-116.

49. Diesel effects on root hydraulic conductivity and morphological changes of the vascular cylinder in Medicago sativa / H.A. Hernández-Ortega, P.A. Quintanar-Isaías, A.T. JaramilloPérez, A. Alarcón, R. Ferrera-Cerrato, R. Lazzarini-Lechuga // Environmental and Experimental Botany. - 2014. - V. 105. P. 1-9.

50. Accumulation of PAHs in tundra plants and soils under the influence of coal mining / E.V. Yakovleva, D.N. Gabov, V.A. Beznosi- 
kov, B.M. Kondratenok, Y.A. Dubrovskiy // Journal Polycyclic Aromatic Compounds. - 2016. - V. 37 (2-3). - P. 1-18.

51. Antioxidant responses of Annelids, Brassicaceae and Fabaceae to pollutants: a review / F. Bernard, F. Brulle, S. Dumez, S. Lemiere, A. Platel, F. Nesslany, D. Cuny, A. Deram, F. Vandenbulcke // Ecotoxicology and Environmental Safety. - 2015. - V. 114. P. 273-303.

52. Влияние загрязнения нефтью и нефтепродуктами на биологическое состояние чернозема обыкновенного / С.И. Колесников, К.Ш. Казеев, М.Л. Татосян, В.Ф. Вальков // Почвоведение. 2006. - № 5. - C. 616-620.

53. Assessing the effect of heavy metals from the Novocherkassk power station emissions on the biological activity of soils in the adjacent areas / T.V. Minnikova, T.V. Denisova, S.S. Mandzhieva, S.I. Kolesnikov, T.M. Minkina, V.A. Chaplygin, M.V. Burachevskaya, S.N. Sushkova, T.V. Bauer // Journal of Geochemical Exploration. - 2017. - V. 174. - P. 70-78.
54. Оценка агроэкологических показателей нефтезагрязненного чернозема Ростовской области при ремедиации мочевиной и гуматом калия / Т.В. Минникова, Т.В. Денисова, С.И. Колесников, Ю.В. Акименко // Российская сельскохозяйственная наука. - 2018. - № 1. - С. 44-48.

55. Трифонова Т.А., Забелина 0.Н. Изменение биологической активности почвы городских рекреационных территорий в условиях загрязнения тяжелыми металлами и нефтепродуктами // Почвоведение. - 2017. - № 4. - С. 497-505.

56. Orecchio S. Contamination from polycyclic aromatic hydrocarbons (PAHs) in the soil of a botanic garden localized next to a former manufacturing gas plant in Palermo (Italy) // Journal of Hazardous Materials. - 2010. - V. 180. - P. 590-601.

57. Effects of root exudates on gel-beads/reeds combination remediation of high molecular weight polycyclic aromatic hydrocarbons / W. Tian, J. Zhao, Y. Zhou, K. Qiao, X. Jin, Q. Liu // Ecotoxicology and Environmental Safety. - 2017. - V. 135. - P. 158-164.

Поступила: 08.11.2018 г.

\section{Информация об авторах}

Минникова T.B., кандидат биологических наук, младший научный сотрудник кафедры экологии и природопользования Академии биологии и биотехнологии Южного федерального университета.

Сушкова $\boldsymbol{C . H . , ~ к а н д и д а т ~ б и о л о г и ч е с к и х ~ н а у к , ~ с т а р ш и и ̆ ~ н а у ч н ы и ̆ ~ с о т р у д н и к ~ к а ф е д р ы ~ п о ч в о в е д е н и я ~ и ~ о ц е н к и ~}$ земельных ресурсов Академии биологии и биотехнологии Южного федерального университета.

Манджиева C.C., кандидат биологических наук, ведущий научный сотрудник кафедры почвоведения и оценки земельных ресурсов Академии биологии и биотехнологии Южного федерального университета.

Минкина T.M., доктор биологических наук, профессор, заведующая кафедрой почвоведения и оценки земельных ресурсов Академии биологии и биотехнологии Южного федерального университета.

Колесников С.И., доктор сельскохозяйственных наук, профессор, заведующий кафедрой экологии и природопользования Академии биологии и биотехнологии Южного федерального университета. 


\title{
ESTIMATION OF THE BENZO[A]PYRENE EFFECT ON BIOLOGICAL ACTIVITY OF ROSTOV REGION CHERNOZEM
}

\author{
Tatiana V. Minnikova',
} loko261008@yandex.ru

Svetlana N. Sushkova', terra_rossa@mail.ru

Saglara S. Mandzhieva', msaglara@mail.ru

Tatiana M. Minkina', tminkina@mail.ru

\author{
Sergey I. Kolesnikov', \\ kolesnikov@sfedu.ru \\ 1 Southern Federal University, \\ 194/1, Stachki avenue, Rostov-on-Don, 344090, Russia.
}

The relevance of the research is caused by the importance in assessing the effect of long-term polycyclic aromatic hydrocarbons contamination using spring barley (Hordeum sativum distichum) on enzymatic activity of chernozems and the morphometric parameters of barley. Spring barley was used to assess the negative impact of chernozem soil pollution with benzo[a]pyrene as a well-known carcinogen and a mutagen among polycyclic aromatic hydrocarbons. The selected doses were close to the level of technogenic pressure in the studied zone: $0-800 \mu \mathrm{g}$ benzo[a]pyrene $\mathrm{kg}^{-1}$. Benzo[a]pyrene content in soils during 4 years of the experiment affected the morphometric parameters of barley and the absorption of benzo[a]pyrene by plants, as well as the enzymatic activity of soils.

The main aim was to assess benzo[a]pyrene effect on the chernozem biological activity in the Rostov Region.

Objects. The investigations were carried out with a sample of soil taken from the upper $(0-20 \mathrm{~cm})$ layer of carbonate heavy loamy chernozem on the territory of the State Soil Preserve "Persian Protected Steppe» located in the Rostov Region (south of the Russian Federation), far from pollution sources. This soil has the following characteristics: $C_{\text {organic }}-3,4 \%, p H-7,3$, exchange capacity cation $37,1 \mathrm{mmol}(+) / 100 \mathrm{~g}^{-1}$; the content of $\mathrm{CaCO}_{3}$ is $0,1 \%$, the content of physical clay is $53,1 \%$.

Methods. Model experiments were carried out under the natural conditions. Two kilograms of air-dry soil were sieved through a 1-mmdiameter sieve and placed into the 4 liters vegetative pots. The benzo[a]pyrene solution in acetonitrile was mixed with the soil to obtain final concentrations of benzo[a]pyrene in soil samples of 20, 200, 400 and $800 \mu \mathrm{g}$ benzo[a]pyrene $\mathrm{kg}^{-1}$ (dry weight), which corresponds to 1, 10, 20 and 40 levels of maximum permissible concentration of benzo[a]pyrene. Clean soil was used as a control and, in addition, a background control was performed where acetonitrile was added similarly to the samples with benzo[a]pyrene.

Results. The main factor influencing the increase in benzo[a]pyrene in soil and plants of model experiment was inoculation dose of toxicant in chernozem ordinary. The activity of oxidoreductase (catalase and dehydrogenases) of chernozem was inhibited with increasing benzo[a]pyrene content in the soil. The greatest toxic effect of benzo[a]pyrene was observed on the activity of dehydrogenases. Tendencies of pronounced phytotoxicity of soils were observed for all morphometric characteristics of spring barley, such as germination energy, length of shoots, plant weight and length of ears. The quantitative absorption levels of benzo[a]pyrene by the roots of spring barley exceeded the vegetative part by more than 2,5 times in all contaminated variants. Thus, the migration of benzo[a]pyrene to shoots and roots of spring barley from chernozem, accompanied by inhibition activity of dehydrogenases and catalase demonstrated the possibility of evaluating bioindication reactions during environmental monitoring to assess the effect of benzo[a]pyrene contamination.

\section{Key words:}

Benzo[a]pyrene, soil, spring barley, morphometry, catalase activity, dehydrogenases activity, correlative dependence.

The research was supported by the projects of Ministry of Education and Science of the RF (no. 5.948.2017/PCh) and by the grant of the President of the Russian Federation (NSH-3464.2018.11; MK-2973.2019.4). The research was carried out using the equipment of the Centre for Collective Use of South Federal University «Biotechnologies, biomedical and ecological monitoring».

\section{REFERENCES}

1. Tsibart A., Gennadiev A. Polycyclic aromatic hydrocarbons in soils: Sources, behavior, and indication significance. Eurasian Soil Science, 2013, vol. 46 (7), pp. 728-741.

2. Jian Y. Photomutagenicity of 16 polycyclic aromatic hydrocarbons from the US EPA priority pollutant list. Mutation Research, 2004, vol. 557, pp. 99-108.

3. Wenzl T., Simon R., Kleiner J., Anklam E. Analytical methods for polycyclic aromatic hydrocarbons (PAHs) in food and the en- vironment needed for new food legislation in the European Union. Trend Analytic Chemistry, 2006, vol. 25 (7), pp. 716-725.

4. Some non-heterocyclic polycyclic aromatic hydrocarbons and some related exposures. Monographs on the Evaluation of Carcinogenic Risks to Humans. Lyon (FR), IARC, 2010. Vol. 92, 862 p.

5. Lamichhane S., Krishna K.B., Sarukkalige R. Polycyclic aromatic hydrocarbons (PAHs) removal by sorption: a review. Chemosphere, 2016, vol. 148, pp. 336-353.

6. Antizar-Ladislao B., Lopez-Real J., Beck A. Degradation of polycyclic aromatic hydrocarbons (PAHs) in an aged coal tar contami- 
nated soil under in-vessel composting conditions. Environmental Pollution, 2006, vol. 141 (3), pp. 459-468.

7. Yakovleva E.V., Beznosikov V.A., Kondratenok B.M., Gabov D.N. Bioaccumulation of polycyclic aromatic hydrocarbons in the soil-plant systems of the northern-taiga biocenoses. Eurasian Soil Science, 2012, vol. 45 (3), pp. 309-320.

8. Kotoky R., Das S., Singha L.P., Pandey P., Singha K.M. Biodegradation of Benzo(a)pyrene by biofilm forming and plant growth promoting Acinetobacter sp. strain PDB4. Environmental Technology \& Innovation, 2017, vol.10, pp. 256-268.

9. Carvalho M., Vila M., Rohden F., Rosas M., Dias J., Oliva-Teles T., Danko A., Delerue-Matos C., Fiuza A. How the sorption of benzene in soils contaminated with aromatic hydrocarbons is affected by the presence of biofuels. Eurasian Journal Soil Science, 2015, vol. 4 (2), pp. 111-117.

10. Maliszewska-Kordybach B., Smreczak B., Klimkowicz-Pawlas A. The levels and composition of persistent organic pollutants in alluvial agriculture soils affected by flooding. Environmental Monitoring Assessment, 2013, vol. 185 (12), pp. 9935-9948.

11. Minkina T., Sushkova S., Mandzhieva S., Tjurina I., Filonova 0. Monitoring researches of the benzo [a] pyrene content in soils under the influence of the technogenic zone. Middle East Journal of Scientific Research, 2013, vol. 17 (1), pp. 44-49.

12. Department for Environment, Food and Rural Affairs and the Environment Agency. Contaminants in soil: Collation of toxicological data and intake values for humans. Benzo[a]pyrene. Technical report. Bristol, Bristol Environment Agency, 2002. 30 p.

13. Lipatov D.N., Shcheglov A.I., Manakhov D.V., Zavgorodnyaya Yu.A., Brekhov P.T. Spatial variation of benzo[a]pyrene and agrozem properties in the vicinity of the Yuzhno-Sakhalinsk thermal power plant. Eurasian Soil Science, 2015. vol. 48, no. 5, pp. 547-554. In Rus,

14. Yakovleva E.V., Beznosikov V.A., Kondratenok B.M., Gabov D.N. Bioaccumulation of polycyclic aromatic hydrocarbons in the soil-plant systems of the northern-taiga biocenoses. Eurasian Soil Science, 2012, vol. 45 (3), pp. 309-320.

15. Gabov D., Beznosikov V., Kondratenok B., Yakovleva E. Polycyclic aromatic hydrocarbons in the soils of technogenic landscapes. Geochemical International, 2010, vol. 48 (6), pp. 569-579.

16. Gennadiev A., Tsibart A. Pyrogenic polycyclic aromatic hydrocarbons in soils of reserved and anthropogenically modified areas: Factors and features of accumulation. Eurasian Soil Science, 2013, vol. 46 (1), pp. 28-36.

17. Aranda R., Martinez-Pagán P. Methodology for the detection of contamination by hydrocarbons and further soil sampling for volatile and semi-volatile organic enrichment in former petrol stations, SE Spain. Eurasian Soil Science, 2012, vol. 1 (1), pp. 10-15.

18. Baldantonia D., Morellia R., Bellinoa A., Vittoria Prati M., Alfania A., De Nicolac F. Anthracene and benzo(a)pyrene degradation in soil is favoured by compost amendment: Perspectives for a bioremediation approach. Journal of Hazardous Materials, 2017, vol. 339, pp. 395-400.

19. Hamdi H., Benzarti S., Manusad`zianas L., Aoyama I., Jedidi N. Bioaugmentation and biostimulation effects on PAH dissipation and soil ecotoxicity under controlled conditions. Soil Biology and Biochemistry, 2007, vol. 39, pp. 1926-1935.

20. Hinsinger P., Gobran G.R., Gregory P.J., Wenzel W.W. Rhizosphere geometry and heterogeneity arising from root-mediated physical and chemical processes. New Phytology, 2005, vol. 168 (2), pp. 293-303.

21. Yang Z., Culvenor R., Haling R., Stefanski A., Ryan M., Sandral G., Kidd D., Lambers H., Simpson R. Variation in root traits associated with nutrient foraging among temperate pasture legumes and grasses. Grass Forage Science, 2015, vol. 72, pp. 93-103.

22. Haling R.E., Yang Z., Shadwell N., Culvenor R.A., Stefanski A., Ryan M.H., Sandral G.A., Kidd D.R., Lambers H., Simpson R.J. Growth and root dry matter allocation by pasture legumes and a grass with contrasting external critical phosphorus requirements. Plant Soil, 2016, vol. 407 (1-2), pp. 67-79.

23. Bisht S., Bioremediation of polyaromatic hydrocarbons (PAHs) using rhizosphere technology. Brazilian Journal Microbiology, 2015, vol. 46 (1), pp. 7-21.

24. Wyszkowska J., Wyszkowski M. Influence of petroleum - derived substances on number of oligotrophic and copitrophic bacteria in soil. American-Eurasian Journal of Agricultural \& Environmental Sciences, 2008, vol. 2 (2), pp. 172-179.

25. Zhan X., Wu W., Zhou L., Liang J., Jiang T. Interactive effect of dissolved organic matter and phenanthrene on soil enzymatic activities. Journal Environmental Science, 2010, vol. 22 (4), pp. 607.

26. Perez-Leblic M.I., Turmero A., Hernandez M., Hernandez A.J., Pastor J., Ball A.S., Rodriguez J., Arias M.E. Influence of xenobiotic contaminants on landfill soil microbial activity and diversity. Journal Environmental Management, 2010, vol. 30 (1), pp. $285-290$.

27. Hawrot-Paw M., Martynus M. The influence of diesel fuel and biodiesel on soil microbial biomass. Polish Journal of Environmental Studies, 2011, vol. 2 (20), pp. 497-501.

28. Bielińska E.J., Żukowska G. Activity of protease and urease in light soil fertilized with sewage sludge. Agrophysica, 2002, vol. 70, pp. 41-47.

29. Wyszkowska J., Wyszkowski M. Activity of soil dehydrogenases, urease and acid and alkaline phosphatases in soil polluted with petroleum. Journal of Toxicology and Environmental Health, 2010, vol. 73, pp. 1202-1210.

30. Tejada M., Gonzalez J.L., Hernandez M.T., Garcia C. Application of different organic amendments in a gasoline contaminated soil: effect on soil microbial properties. Bioresource Technology, 2008, vol. 99, pp. 2872-2880.

31. GOST 17.4.1.02.-83. Sokhranenie. Pochvy. Klassifikatsiya khimicheskikh veshchesto dlya borby s zagryazneniem [State Standard 17.4.1.02.-83. Preservation. Soil. Classification of chemicals to control pollution]. Moscow, Standard Publ. house, 2008. $8 \mathrm{p}$.

32. Batukaev A.A., Endovitsky A.P., Andreev A.G., Kalinichenko V.P., Minkina T.M., Dikaev Z.S., Mandzhieva S.S., Sushkova S.N. Ion association in water solution of soil and vadose zone of chestnut saline solonetz as a driver of terrestrial carbon sink. Solid Earth, 2016, vol. 7 (2), pp. 415-423.

33. Minkina T., Pinsky D., Mandzhieva S., Bauer T., Sushkova S., Kushnareva A. Effect of an Attendant Anion on the Balance of Cations in the Soil-Solution System with an Ordinary Chernozem as an Example. Eurasian Soil Science, 2014, vol. 47 (8), pp. $772-780$.

34. Sushkova S., Minkina T., Turina I., Mandzhieva S., Bauer T., Kizilkaya R., Zamulina I. Monitoring of benzo[a]pyrene content in soils under the effect of long-term technogenic pollution. Journal Geochemical Exploration, 2017, vol. 174, pp. 100-106.

35. Sushkova S., Vasilyeva G., Minkina T., Mandzhieva S., Tyurina I., Kolesnikov S., Kizilkaya R., Askin T. New method for benzo[a]pyrene analysis in plant material using subcritical water extraction. Journal Geochemical Exploration, 2014, vol. 144 (P. B), pp. 267-272.

36. Sushkova S.N., Minkina T.M., Mandzhieva S.S., Vasilyeva G.K., Borisenko N.I., Turina I.G., Kizılkaya R. New alternative method of benz[a]pyrene extractionfrom soils and its approbation in soil under technogenic pressure. Journal of Soils and Sediments, 2016, vol. 16 (4), pp. 1323-1329.

37. Lekar A., Borisenko S., Vetrova E., Sushkova S., Borisenko N. Extraction of quercetin from Polygonum hydropiper L. by subcritical water. American. Journal of Agricultural and Biological Science, 2013, vol. 9 (1), pp. 1-5.

38. Sushkova S., Minkina T., Mandzhieva S., Borisenko N., Vasilyeva G., Kizllkaya R., Aikin T. Approbation of express-method for 
benzo[a]pyrene extraction from soils in the technogenic emission zone territories. Eurasian Journal Soil Science, 2015, vol. 4 (1), pp. $15-21$.

39. Dadkhah A., Akgerman A. Hot water extraction with in situ wet oxidation: Kinetics of PAHs removal from soil. Journal Hazard Materials, 2006, vol. 137 (1), pp. 518-526.

40. Lagadec A., Miller D., Lilke A., Hawthorne S. Pilot-scale subcritical water remediation of polycyclic aromatic hydrocarbon- and pesticide-contaminated soil. Environ Science Technology, 2000, vol. 34(8), pp.1542-1548.

41. Latawiec A., Reid B. Sequential extraction of polycyclic aromatic hydrocarbons using subcritical water. Chemosphere, 2010, vol. 78 (8), pp. 1042-1048.

42. Galkin A., Lunin V. Water in sub- and supercritical conditions is a univer-salfluid for implementation of chemicalreactions. Success Chem., 2005, vol. 74 (1), pp. 24-40.

43. ISO 13877-2005. Soil quality - Determination of polynuclear aromatic hydrocarbons - Method using high-performance liquid chromatography. 2005. $15 \mathrm{p}$.

44. Agrokhimicheskie metody issledovaniya pochv [Agrochemical methods of soil research]. Ed. by A.V. Sokolov. Moscow, Nauka Publ., 1975. $656 \mathrm{p}$.

45. Galstyan A.Sh. Fermentativnaya aktivnost pochv Armenii [Enzymatic activity of soils in Armenia]. Yerevan, Hayastan Publ., $1974.275 \mathrm{p}$.

46. Tserling V.V. Diagnostika pitaniya selskokhozyastvennykh kultur. Spravochnik [Diagnostics of crop nutrition. Directory]. Moscow, Agropromizdat Publ., 1990. 236 p.

47. Sushkova S.N., Minkina T., Deryabkina (Turina) I., Mandzhieva S., Zamulina I., Bauer T., Vasilyeva G., Antonenko E., Rajput $\mathrm{V}$. Influence of PAH contamination on soil ecological status. Journal of Soils and Sediments, 2018, vol. 18 (6), pp. 2368-2378.

48. Sushkova S.N., Minkina T.M., Mandzhieva S.S., Deryabkina I.G., Vasil'eva G.K., Kızılkaya R. Dynamics of benzo $[\alpha]$ pyrene accumulation in soils under the influence of aerotechnogenic emissions. Eurasian Soil Science, 2017, vol. 50, no. 1. pp. 95-105. In Rus.

49. Hernández-Ortega H.A., Quintanar-Isaías P.A., JaramilloPérez A.T., Alarcón A., Ferrera- Cerrato R., Lazzarini-Lechuga R. Diesel effects on root hydraulic conductivity and morpholo- gical changes of the vascular cylinder in Medicago sativa. Environmental and Experimental Botany, 2014, vol. 105, pp. 1-9.

50. Yakovleva E.V., Gabov D.N., Beznosikov V.A., Kondratenok B.M., Dubrovskiy Y.A. Accumulation of PAHs in tundra plants and soils under the influence of coal mining. Journal Polycyclic Aromatic Compounds, 2016, vol. 37 (2-3), pp. 1-18.

51. Bernard F., Brulle F., Dumez S., Lemiere S., Platel A., Nesslany F., Cuny D., Deram A., Vandenbulcke F. Antioxidant responses of Annelids, Brassicaceae and Fabaceae to pollutants: a review. Ecotoxicology and Environmental Safety, 2015, vol. 114, pp. 273-303.

52. Kolesnikov S.I., Kazeev K.Sh., Tatosyan M.L., Val'kov V.F. The effect of pollution with oil and oil products on the biological status of ordinary chernozems. Eurasian Soil Science, 2006, vol. 39, no. 5, pp. 552-556. In Rus.

53. Minnikova T.V., Denisova T.V., Mandzhieva S.S., Kolesnikov S.I., Minkina T.M., Chaplygin V.A., Burachevskaya M.V., Sushkova S.N., Bauer T.V. Assessing the effect of heavy metals from the Novocherkassk power station emissions on the biological activity of soils in the adjacent areas. Journal of Geochemical Exploration, 2017, vol. 174, pp. 70-78.

54. Minnikova T.V., Denisova T.V., Kolesnikov S.I., Akimenko Yu.V. Assessment of agroecological indicators of oil-contaminated chernozem in Rostov oblast after remediation with urea and potassium humate. Russian Agricultural Sciences, 2018, vol. 44, no. 2, pp. 177-182. In Rus.

55. Trifonova T.A., Zabelina 0.N. Changes in the biological activity of heavy metal- and oil-polluted soils in urban recreation territories. Eurasian Soil Science, 2017, vol. 50, no. 4, pp. 483-490. In Rus.

56. Orecchio S. Contamination from polycyclic aromatic hydrocarbons (PAHs) in the soil of a botanic garden localized next to a former manufacturing gas plant in Palermo (Italy). Journal of $\mathrm{Ha}$ zardous Materials, 2010, vol. 180, pp. 590-601.

57. Tian W., Zhao J., Zhou Y., Qiao K., Jin X., Liu Q. Effects of root exudates on gel-beads/reeds combination remediation of high molecular weight polycyclic aromatic hydrocarbons. Ecotoxicology and Environmental Safety, 2017, vol. 135, pp. 158-164.

Received: 08 November 2018.

Information about the authors

Tatiana V. Minnikova, Cand. Sc., junior researcher, Southern Federal University.

Svetlana N. Sushkova, Cand. Sc., senior researcher, Southern Federal University.

Saglara S. Mandzhieva, Cand. Sc., leading researcher, Southern Federal University.

Tatiana M. Minkina, Dr. Sc., professor, head of the department, Southern Federal University.

Sergey I. Kolesnikov, Dr. Sc., professor, head of the department, Southern Federal University. 